\title{
Rio das Ostras, cidade do jazz. Contribuição da música para o bem-estar e desenvolvimento local alcançados nesse território
}

\author{
Rio das Ostras, city of jazz. Contribution of music to the welfare and \\ local development achieved in this territory
}

\author{
Rio das Ostras, ciudad del jazz. Contribución de la música para el \\ bienestar y desarrollo local logrado en este territorio
}

\author{
Micael Herschmann | micaelmh@globo.com \\ Programa de Pós-Graduação em Comunicação da UFRJ \\ Indira Rodrigues de Oliveira | indiraroliveira@gmail.com \\ Programa de Pós-Graduação em Comunicação da UFRJ \\ Cintia Sanmartin Fernandes | cintia@lagoadaconceicao.com \\ Programa de Pós-Graduação em Comunicação da UFRJ
}

\section{RESUMO}

A partir não só de levantamento de matérias veiculadas na mídia tradicional e de dados socioeconômicos do território, mas também de observações de campo, conversas informais e entrevistas semiestruturadas (realizadas com lideranças, moradores, autoridades, produtores e fãs de jazz), busca-se neste artigo avaliar o papel da música (ao lado dos royalties do petróleo) nos patamares de desenvolvimento alcançados pela cidade de Rio das Ostras (na região Norte- Fluminense). Em outras palavras, busca-se repensar a relevância do conhecido Festival de Jazz \& Blues de Rio das Ostras nos processos de ressignificação dessa urbe, isto é, a capacidade desse evento musical contribuir para a integração social do território (ampliando as sinergias entre os atores e instituições da região), a geração de novos empregos e uma melhoria significativa da qualidade de vida e bem-estar da população local.

Palavras-chave: Comunicação; música; cultura urbana; políticas públicas; desenvolvimento local. 


\section{ABSTRACT}

Based on articles published in traditional media and socioeconomics information of the territory, as well as field observations, conversations and semi-structured interviews (with leaders, residents, authorities, producers and jazz fans), the aim of this study is to evaluate the role of music (along with oil royalties) in the level of development reached by the town of Rio das Ostras (in the northern region of Rio de Janeiro). In other words, it seeks to rethink the relevance of the renowned Jazz and Blues Festival of Rio das Ostras in the processes of re-signification of this place, that is, the capacity of this musical event to contribute to the social integration of the territory (increasing the synergies between the actors and institutions of this region), the generation of new jobs and a significant improvement in the quality of life and well-being of the local population.

Keywords: Communication; music; urban culture; public policy; local development.

\section{RESUMEN}

Tomando en cuenta no solo artículos publicados en los medios tradicionales einformaciones socioeconómicas del territorio, pero también las observaciones de campo, conversaciones y entrevistas semiestructuradas (con líderes, residentes, autoridades, productores y aficionados al jazz) el objetivo de este artículo es evaluar la contribución de la música (al lado de los royalties del petróleo) en los niveles de desarrollo alcanzados por la ciudad de Rio das Ostras (norte de Río de Janeiro). En otras palabras, busca analizar el relieve del conocido Festival de Jazz \& Blues de Rio das Ostras en el proceso de re-significación de la ciudad, es decir, la capacidad de este evento musical contribuir para la integración social del territorio (promoviendo sinergias entre actores e instituciones en esta región), la generación nuevos puestos de trabajo, y mejorías significativas de la calidad de vida y el bienestar de la población local.

Palabras claves: Comunicación; música; cultura urbana; políticas públicas; desarrollo local.

Contribuição dos autores: todos os autores são responsáveis pelas fases do artigo

Declaração de conflito de interesses: não houve.

Fontes de financiamento: não houve.

Considerações éticas: não há.

Histórico do artigo: Submetido: 06.maio.2017 | Aceito: 13.maio.2017 | Publicado: 30.jun.2017.

Apresentação anterior: não houve.

Licença CC BY-NC atribuição não comercial. Com essa licença é permitido acessar, baixar (download), copiar, imprimir, compartilhar, reutilizar e distribuir os artigos, desde que para uso não comercial e com a citação da fonte, conferindo os devidos créditos de autoria e menção à Reciis. Nesses casos, nenhuma permissão é necessária por parte dos autores ou dos editores. 


\section{Introdução}

Busca-se ao longo deste artigo repensar as articulações e tensões entre comunicação, cultura e espacialidade na cidade de Rio das Ostras. É sempre válido sublinhar que a música não é só expressão cultural, mas é também uma forma de comunicação poderosa ${ }^{1}$, pois tem uma enorme capacidade de mobilizar os atores, o que permite a construção de territorialidades significativas ${ }^{2}$. Parte-se do pressuposto de que no Rio de Janeiro a sonoridade tem papel mais destacado em função da presença de uma cultura musical de muita vitalidade no estado, como vem sendo ressaltado em artigos publicados nos últimos anos. Portanto, constitui-se em um vetor importante de transformação ou ressignificação social ${ }^{3}$.

Os argumentos apresentados aqui foram construídos especialmente tomando-se como referência as observações de campo realizadas nos últimos anos (antes, durante e depois das edições dos festivais) e as entrevistas informais e semiestruturadas realizadas com os atores (músicos, produtores de festival, donos de pousadas, políticos locais e fãs dos festivais). Vale dizer que esse material especificamente foi um importante aliado para problematizar os códigos e as decodificações presentes no contexto estudado ${ }^{4}$. Como esta investigação tem interesse também nos ecossistemas socioculturais existentes, de pouca evidência e/ ou pouco institucionalizados nas urbes, ficam no ar as seguintes indagações: de que modo é possível vencer a invisibilidade de várias dinâmicas que são efetivamente transformadoras? Isto é, como construir uma metodologia de pesquisa que não só pretende problematizar os protocolos de pesquisa 'viciados', mas que também permita seguir os atores, construir uma 'cartografia sensível' (sintonizada com a Teoria Ator-Rede) e não deixe de levar em conta as fabulações, "táticas e astúcias"5 dos atores no cotidiano? Certamente, não é privilegiando apenas as matérias jornalísticas, dados estatísticos gerados pelas instituições e/ou adotando a perspectiva tecnocrática da maioria dos setores dos órgãos públicos.

Vale ressaltar também que este artigo traz alguns dos resultados parciais de uma pesquisa mais ampla que busca analisar a relevância da cultura musical desenvolvida no espaço público de cidades como Rio das Ostras, Conservatória e Rio de Janeiro (especialmente na área central desta metrópole), a qual vem sendo desenvolvida já há alguns anos com apoio do CNPq. Nesse sentido, o objetivo principal desta investigação em curso é avaliar - a partir dos estudos de caso das cidades mencionadas - a importância das atividades musicais realizadas ao vivo e nos espaços públicos e privados por artistas, coletivos e/ou redes sociais para a ressignificação dessas urbes do estado do Rio de Janeiro. Ou seja, busca-se analisar a capacidade que têm essas atividades culturais de colaborar significativamente para converter esses territórios em espaços mais democráticos (com melhores níveis de inclusão e participação social) e com dinâmicas mais interculturais. Com essa pesquisa visa-se também subsidiar a reconstrução de uma agenda de políticas públicas (com foco na área cultural) mais democrática, colaborando assim, entre outras coisas, para o fomento da diversidade cultural regional e para o desenvolvimento local mais equilibrado e sustentável do estado do Rio de Janeiro.

Poder-se-ia indagar por que essa discussão é importante para o debate de desenvolvimento local sustentável (DLS) dos territórios?ii As iniciativas musicais - espontâneas e organizadas - realmente trazem inúmeras 'externalidades' positivas (desdobramentos socioeconômicos) para os territórios? Entre as iniciativas mais planificadas, qual seria exatamente a relevância dos grandes festivais (de música), especialmente em cidades de pequeno e médio porte como Rio das Ostras?

Refletindo especificamente sobre o estudo de caso tratado aqui: vale lembrar que há uma extensa literatura - especialmente anglo-saxã ${ }^{6}$ - que considera que o momento de organização e realização do festival (especialmente de médio e grande porte), por ser um acontecimento que agrega os atores de

\footnotetext{
i Vale salientar que o debate efetivamente contemporâneo em torno do desenvolvimento não passa, hoje, por uma perspectiva desenvolvimentista - que durante muitos anos mobilizou o imaginário de técnicos e intelectuais brasileiros -, mas sim pelas discussões associadas ao desenvolvimento local, bem como por aquelas referentes à necessária articulação entre os diversos atores envolvidos no processo de desenvolvimento ${ }^{17,19}$
} 
diferentes segmentos sociais (produz sinergias entre grupos mais ou menos organizados, empresários e Estado), é que poderia alavancar não só o desenvolvimento local (a cultura emergiria na atualidade como um 'recurso'), mas também uma sociabilidade mais cosmopolita e até instaurar relações mais "interculturais" em um território. Ora, sem discordar inteiramente dessa literatura, o que a investigação em curso vem problematizando é que isso eventualmente acontece em algumas cidades, mas há processos e desdobramentos que vão em outras direções e exigem uma reflexão mais densa e rigorosa.

Analisando de maneira crítica a maioria das intervenções orquestradas pelo poder público e pelo capital (local e transnacional) - com mais, ou menos, apoio dos atores - no mundo contemporâneo globalizado (especialmente nos países periféricos), é possível atestar que inúmeras vezes os políticos e autoridades afirmam junto a diferentes setores das sociedades que estão construindo uma 'cidade criativa', mas frequentemente o que se assiste é a implementação de um conjunto de "estratégias de city marketing" ". Ao avaliarmos o planejamento e as intervenções conduzidas nessas urbes, constatamos que na maioria das vezes os processos são exógenos, operando a partir de uma lógica mimética (copiam-se modelos de metrópoles supostamente exitosas) e/ou de forma ostentatória (valoriza-se tudo que possa ser excessivamente espetacularizado). Em geral esses tipos de eventos estão muito mais voltados para produção de sinergias com o branding territorial: envolvem frequentemente a construção de equipamentos urbanos e buscam atrair turistas e investimentos (que visam em última instância não gerar DLS, mas sim enriquecer investidores e grupos políticos específicos; desse modo, os objetivos são financeiros e de crescimento da máquina urbana).

Portanto, por um lado, há que reconhecer que existem também processos de "festivalização de uma cidade"6 os quais redundam em projetos excludentes (em geral, voltados para o turismo e para a elite econômica) de gentrificação e alijamento da população mais pobre que vê negado o seu 'direito à cidade'. Por outro, muitas vezes as localidades se constituíram ao longo de períodos significativos de tempo (no cotidiano) como territórios possuidores de uma cultura musical potente através de iniciativas envolvendo os músicos, redes de fãs e empreendedores, que geram eventos de pequeno e médio porte que não necessariamente passam direta ou indiretamente pelo apoio ou intervenções levadas a cabo pelo poder público.

\section{Breve história de Rio das Ostras e o Festival de Jazz \& Blues}

É inegável que o Festival de Jazz \& Blues ${ }^{\text {iiii }}$ surge como um atrativo muito relevante para a cidade de Rio das Ostras. Geralmente relacionado a um estilo de vida elitista e espaços culturais privados em diversas cidades brasileiras ${ }^{8}$, esses gêneros musicais invadiram as ruas desse balneário, atraindo segmentos expressivos para os espaços públicos, passando a mobilizar uma rede de fãs. Este nicho do mercado do jazz vem assim crescendo exponencialmente nos últimos anos ${ }^{3}$, mobilizando um público de diferentes segmentos sociais e de várias faixas etárias, especialmente formado pelos mais jovens.

Localizada a apenas $170 \mathrm{~km}$ da capital do estado, Rio das Ostras construiu uma cena cultural à margem e à sombra da glamorosa cidade do Rio e de Búzios. Esse balneário só teve sua emancipação políticoadministrativa em 1992, desde então apresentando um crescimento de aproximadamente $11 \%$ ao ano - considerado o maior do estado -, em uma área territorial de $232 \mathrm{~km}^{2}$. Rio das Ostras assistiu a um crescimento exponencial em seu número de moradores a partir do início da exploração de petróleo na Bacia de Campos em Macaé (cidade litorânea vizinha de Rio das Ostras), tendo atualmente uma média de 115 mil habitantes. A população está distribuída em uma área territorial de 229,50 $\mathrm{Km}^{2}$ de extensão, com mais

ii Evidentemente, o jazz é um gênero musical com uma história específica, mas neste artigo ele é considerado como parte de um nicho de mercado que engloba também a música instrumental e o blues. Tendo em vista que não só inúmeros atores sociais fazem essa associação, mas também que há hegemonia de uma interpretação difusa do gênero (uma espécie de leitura 'free jazz') no Brasil - que dificulta o estabelecimento de fronteiras claras (especialmente mercadológicas) -, optou-se por associá-lo a outros gêneros musicais neste artigo. 
de 90\% na zona urbana do município. Rio das Ostras possui uma localização estratégica na Região dos Lagos - a Costa do Sol -, com mais de $28 \mathrm{~km}$ de litoral, águas limpas e tranquilas. Além disso, o mercado presente é capacitado com cerca de 65 hotéis e pousadas, oferecendo mais de 2.500 opções de hospedagem. Tais fatores, aliados a um clima tropical, são alguns dos que facilitaram o turismo de verão ter se tornado uma importante fonte de renda local. Contudo, a partir de 2003, os habitantes da cidade de Rio das Ostras assistiram a uma lenta mudança em seu ambiente local por conta da introdução do festival de jazz e blues. No decorrer de alguns anos, muros, ruas e becos degradados e abandonados foram ressignificados, muitas vezes com sonoridades, imagens (cartazes e pinturas) e até esculturas de instrumentos musicais. Alguns bares passaram a se chamar pubs e, no palco de música ao vivo, uma vez ao ano, o axé passou a dar espaço a um estilo de música diferente. Escolas de música foram construídas, corais foram endossados e em pouco tempo Rio das Ostras passou a ser proclamada pela prefeitura local como a "Cidade do Jazz" por conta do destaque desse evento anual. O festival, que começou em 2003, é público, gratuito e, em geral, conta com a participação de atrações locais, nacionais e internacionais. Analisando a trajetória de todas as edições, o evento dura entre 4 e 7 dias e a programação é espalhada em alguns palcos pela cidade.

De acordo com estudo realizado pela Secretaria Municipal Turismo, Indústria e Comércio (Semtic), no ano de 2002, o turismo em Rio das Ostras foi responsável por 20,18\% do que correspondeu a uma movimentação financeira direta e indireta de R \$ 50.657.815,70. Essa atividade gerou, no mesmo ano, 1.881 postos de trabalho diretos e indiretos na alta temporada e 1.166 na baixa temporada ${ }^{9}$. Conforme argumenta-se no relatório de demanda da cidade de Rio das Ostras (2014), disponibilizado por Edmilson Oliveira, assessor da Secretaria de Turismo de Rio das Ostras, o aumento do interesse turístico na cidade na época do Festival de Jazz \& Blues é marcante: para os técnicos que elaboraram o documento, o festival é o evento de maior atrativo de turistas da cidade e o único que atrai o consumidor de 26 a 55 anos, de alto poder aquisitivo - a grande maioria possui ensino superior completo, se hospeda em pousadas e vem para a cidade com automóvel próprio. A secretária de turismo da cidade (durante a realização dessa etapa da pesquisa), Carla Ennes, afirma que em 2004 foi encomendado um estudo de demanda para a Fundação Getúlio Vargas (FGV), que comprovou que a presença de 50\% dos turistas naquele verão se dava por conta do festival. Tal estudo garantiu a permanência do evento para a agenda de 2005 e motivou a mudança para período de baixa temporada (inverno) em 2006. No sétimo ano do evento, o festival já era considerado um dos mais importantes da América Latina. Para que se tenha uma ideia, em 2014 o evento possibilitou a injeção de cerca de $\mathrm{R} \$ 11$ milhões na economia do município em cinco dias, segundo pesquisa realizada pela Secretaria Municipal de Turismo, novamente em parceria com a FGV. A mídia espontânea gerou um retorno para a cidade de cerca de $\mathrm{R} \$ 3$ milhões, comprovada pelo interesse e credenciamento de 80 jornalistas da mídia impressa e eletrônica. Consequentemente, poder-se-ia afirmar que esse evento vem possibilitando, de forma significativa, a geração de rendas/empregos, bem como o incremento da economia no município há mais de uma década.

Segundo os atores entrevistados, o festival teria condições de cobrar uma taxa de entrada e o público provavelmente não se abdicaria de pagá-la, porém a organização do evento se recusa a adotar este procedimento. Não apenas isso, os palcos são estrategicamente posicionados para não só possibilitarem fácil acesso de todos na cidade, como também promover ao turista que não conhece Rio das Ostras a possibilidade de cruzar os pontos mais importantes da região enquanto segue as atrações do evento. O comércio que rodeia o festival na Costazul se divide entre as barracas licenciadas pela produção e aqueles ambulantes que simplesmente seguem o público, em geral, vendendo mercadoria mais barata. Em alguns palcos da cidade os comerciantes contratados e aqueles informais se misturam, sendo diferenciados apenas pelo uniforme que a prefeitura disponibiliza para aqueles que se registraram com antecedência.

A essa altura, é preciso salientar que o festival não gera apenas externalidades positivas sobre o território. O cotidiano da cidade de Rio das Ostras é alterado no período em que o festival acontece: por um lado, os 
habitantes da cidade sofrem com o aumento de preços, a superlotação da cidade (que gera, entre outros problemas, a falta de água nas torneiras, aumento expressivo dos lixos nas ruas e a queda na qualidade dos serviços oferecidos a todos) e a intensificação do trânsito, entre outros transtornos; por outro, como já sublinhamos, surgem novas oficinas de música, oportunidades para o comércio local, incentivos acadêmicos e até a revitalização de ambientes e equipamentos urbanos que estão abandonados ou relegados a um segundo plano pela administração pública local.

A gratuidade do evento parece desempenhar um importante papel no agenciamento dessa cultura musical pelos atores desse território. Como já foi assinalado, os moradores de Rio das Ostras (riostrenses), desde de 2003, convivem com a ocorrência anual do Festival de Jazz \& Blues na cidade. Ao longo desses anos é possível atestar que o público local tem se mostrado crescentemente participativo, mesmo quando não adepto aos "gêneros musicais" ${ }^{10} \mathrm{em}$ pauta, promovendo assim processos de ressignificação no cotidiano de Rio das Ostras. Por exemplo, no ano de 2014, foi detectada a presença de $74 \%$ de riostrenses durante as atrações principais. Além disso, nos períodos pelos quais perduram o Festival de Jazz \& Blues, as diferenças sociais tão evidentes na forma de ocupação de espaços de Rio das Ostras são de certa forma diluídas, instaurando-se na cidade uma dinâmica mais "intercultural" 11

Assim, a partir de um levantamento realizado, foi possível nos últimos anos constatar nessa cidade musical uma dinâmica muito interessante. Segmentos da população menos privilegiada da cidade parecem estar lentamente se apropriando do jazz, que primeiramente foi considerado pelas lideranças locais um gênero musical capaz de alavancar um turismo mais direcionado para as camadas médias. O surgimento de uma "cena musical"12 local, de apreciadores do Jazz \& Blues (ainda que um pouco incipiente), indica a possibilidade de que a população da cidade esteja em processo de "reconversão cultural" ${ }^{13}$. É possível que venha emergindo em Rio das Ostras uma pequena cena (alternativa) na localidade. A constante presença de uma banda riostrense Segundo Set - que toca regularmente no bar Galeto de Macaé e na Casa de Cultura (localizada no bairro de Unamar) - e o surgimento de dinâmicas envolvendo músicos isolados e grupos que tocam em barzinhos e casas noturnas em troca de cachê para um público local expressivo são indícios significativos.

Portanto, a dimensão afetiva e sensível também é um vetor que "enraíza dinamicamente"14 essa cultura musical naquele território. Não só o produtor Stênio Mattos possui claramente um laço afetivo com essa localidade (vem afirmando isso explicitamente em vários depoimentos), mas também se percebe que a maior parte dos moradores da cidade aceitou o festival como uma novidade positiva em seu cotidiano social na década passada, representando para eles um incremento da vida cultural local e mais um acontecimento que possibilita encontros, um "estar-junto"14, uma sociabilidade relevante no seu cotidiano. Assim, as edições do festival geram expectativas não apenas nos turistas que frequentam e vivem o festival, mas também na população local - de variadas faixas etárias - convertida em "redes de fãs" ${ }^{15}$ desse universo cultural. O fato foi observado pela secretária de turismo em exercício no ano de 2016, Carla Ennes:

De uns tempos para cá a população da cidade começou a querer participar mais do festival. Acho que a criação da UFF, do curso de produção cultural na cidade foi significativo e colaborou para isso. O pessoal mais jovem começou a estar mais integrado com o evento. Quando veio o curso de produção cultural, o público do festival foi ficando mais jovem. Porque no início a gente viu apenas o pessoal mais velho participando do festival [...]. Portanto, de uns anos para cá o público mais jovem passou a estar presente. .iiiii $^{\text {in }}$

Ainda que em Rio das Ostras não tenha ocorrido um conjunto de mudanças físicas e estruturais com a chegada do Festival de Jazz \& Blues, são as alterações sociais e afetivas que mais parecem chamar a atenção para o papel desempenhado por esse evento. São essas também que parecem manter o evento vivo apesar

iii Entrevista com Carla Ennes concedida no dia 7 julho de 2015. 
das dificuldades financeiras das últimas edições que estão relacionadas como a crise econômica que vem se alastrando no país desde 2014 (associadas, entre outras coisas, ao decréscimo do valor dos royalties gerados pelo petróleo extraído na Bacia de Campos, que financiavam boa parte dos investimentos - inclusive culturais - nos municípios da região Norte do estado do Rio de Janeiro). Segundo os atores pesquisados, o festival é também um 'patrimônio afetivo da cidade' e, ao que tudo indica, mantém-se principalmente pela vontade das lideranças locais.

Apesar desse processo de apropriação cultural em curso, evidentemente, é preciso destacar o papel de algumas lideranças na cidade. O produtor Stenio Mattos - com o apoio de indivíduos que estão posicionados em várias instâncias do poder local - desempenha claramente um papel- chave na criação e continuidade do evento. Até mesmo os indivíduos com muito poder na localidade parecem estar de alguma maneira submetidos à liderança de Mattos. Vale destacar que este produtor centraliza inúmeras funções estratégicas na organização do festival: tem uma relação direta com as diferentes mídias que cobrem o evento, gerencia a verba captada e que vem sendo utilizada no festival e parece controlar todas as pequenas decisões que afetam a logística do evento no território (mudanças na circulação de pessoas e veículos, volume do número de assentos próximos aos palcos e ruas etc.).

\section{Desafios ao desenvolvimento local}

Como já mencionado anteriormente, busca-se aqui repensar a relevância desse renomado festival de jazz nos processos de ressignificação dessa urbe, isto é, a capacidade desse evento musical contribuir para a integração social do território (ampliando as sinergias entre atores e instituições), a geração de novos empregos e uma melhoria significativa da qualidade de vida e do bem-estar da população local.

Outras hipóteses sobre o patamar de desenvolvimento desse território foram contempladas: poder-se-ia considerar se não seriam todas essas transformações territoriais e sociais em Rio das Ostras apenas um desdobramento do crescimento da exploração de petróleo na Bacia de Campos (Macaé, RJ), iniciada na década de 1970, ao invés de uma nova dinâmica territorial impactada em grande medida pelo festival de jazz? Neste sentido, poder-se-ia indagar: como ficará esta cidade balneária se a crise do petróleo - que começou em 2014 - continuar produzindo seus efeitos socioeconômicos sobre a região e o país.

Assim, se por um lado, Rio das Ostras mostra-se abalada pela conjuntura atual de crise do petróleo, por outro, não vem sucumbindo inteiramente a uma condição de estagnação socioeconômica por conta de suas altas taxas de turismo relacionadas às atividades culturais que promovem a cidade. O estudo que vem sendo realizado tem indicado que investir nas atividades criativas e culturais está se constituindo em uma alternativa para manter os indicadores de turismo. Portanto, os atores entrevistados salientam em seus depoimentos que não só o Festival de Jazz \& Blues de Rio das Ostras, mas também outros eventos que compõem com destaque o calendário local têm se mostrado relevantes para a construção de uma estratégia alternativa de desenvolvimento viável neste contexto de crise. Aliás, de acordo com a webpage do programa Cidades Sustentáveis:

O município [de Rio das Ostras] hoje é considerado referência em iniciativas culturais permanentes que deram início a programas e projetos de geração de emprego e renda, aliados ao princípio da autogestão financeira da Fundação Rio das Ostras de Cultura, instituição que gerencia as ações do setor no município. iviv 
Ainda que exista certo consenso entre os atores e lideranças do que representam as atividades culturais - especialmente o festival de jazz - articuladas ao turismo na região, não há uma postura colaborativa e um consenso em relação as estratégias a serem adotadas no território. Ainda parece haver um posicionamento distanciado e pouco associativo entre os atores, continua-se esperando que o protagonismo seja desempenhado por Mattos e/ou pela tecnocracia da prefeitura (pelas autoridades locais).

Pelo que já foi apurado até o momento, o estudo de caso de Rio das Ostras indica que o festival como estratégia deflagradora de processos que podem alavancar o desenvolvimento só adquirirá mais efetividade se for incorporado de forma endógena pelos atores locais. Do contrário, corre o risco de se tornar uma espécie de 'receita' (tese de que esse modelo poderia ser aplicado a outros espaços, independentemente das características locais) paliativa e pode até se tornar uma estratégia pontual de city marketing que alcança alguns resultados positivos, mas, de modo geral, provavelmente trará poucos benefícios ao território a médio e longo prazo. Assim, a existência do festival por treze anos e sua importância econômica para a cidade (sua incorporação através de políticas culturais locais) pode ser um fator crucial de crescimento para uma cidade, desde que haja mais engajamento e associativismo entre os atores no território.

Há certo consenso de que o território carece de mais 'associativismo' e os atores de mais protagonismo, inclusive isso conduziu à criação da Fundo e Conselho Municipal de Cultura em 2016. Segundo Alcebíades Sabino, prefeito do balneário naquele ano, a falta de um fórum entre os atores e de uma cultura associativista levou a atual gestão a criar esse Fundo Municipal e Conselho para a cidade de Rio das Ostras. A intenção dessa medida é exatamente propiciar um ambiente de mais "governança" ${ }^{16}$ para que se possa construir de forma mais objetiva e democrática uma estratégia de desenvolvimento para a cidade que tenha as atividades culturais como epicentro.

Eu acho que a criação do Fundo e do Conselho Municipal vai buscar dar um mínimo de organização [ao movimento artístico da cidade]. É muito difícil fazer a gestão equilibrada dos recursos públicos visando ao desenvolvimento da cidade, especialmente voltada para o setor da cultura e do turismo. É preciso criar um espaço de diálogo com a sociedade, com os artistas, comerciantes e pousadeiros [...]. É importante que a sociedade seja também ouvida e conscientizada da importância desses investimentos para a cidade. Precisamos construir um ambiente de mais colaboração na cidade para enfrentar este contexto de crise econômica da região do Norte do estado do Rio e do país. ${ }^{v v}$

Assim, foi possível atestar, até aqui, que a crise do petróleo e os riscos de descontinuidade do festival que emergiram nos dois últimos anos, vem lançando desafios não só para a cidade, mas também a este estudo em curso nesse território. Portanto, tendo em vista o que já foi sinalizado neste artigo - a partir dos depoimentos dos atores (divididos em categorias, segundo seus interesses), a situação do festival é mais complexa (e se encontra sob possível ameaça) do que parece a princípio, colocando um campo de possibilidades no horizonte. Aliás, é possível encontrar nos depoimentos das autoridades, artistas e pousadeiros um "esboço" desses possíveis desdobramentos.

\section{Depoimentos das autoridades locais}

Constatou-se neste estudo que a edição de 2016 do festival foi realizada em meio a muita dificuldade e sob intensa descrença por parte dos consumidores e até dos seus realizadores. No entanto, uma vez que o evento aconteceu a despeito das expectativas pessimistas (de certo modo, apresentando relativo sucesso no

V Entrevista com Alcebíades Sabino concedida no dia 17 novembro de 2016. 
que se refere à presença de público), muitos atores começaram a se perguntar, por exemplo, se ele não teria adquirido um pouco mais de independência em relação aos aspectos condicionantes econômicos (ao estilo de outros festivais indie realizados no Brasil) uma vez que, mesmo na sua versão mais simples, esse evento segue atraindo segmentos sociais expressivos da cidade e de fora nos últimos dois anos. O produtor Stênio Mattos identificou na participação do público um apoio declarado ao evento na sua edição 2016.

Este ano as pessoas não foram imbuídas de um olhar crítico. Foram ao evento para dar uma força e reiteraram que o evento não podia acabar, que tudo estava bonito, apesar de todas as dificuldades. A população local comprou o festival na sua versão mais modesta e quer que o evento continue. ${ }^{\text {vivi }}$

Tal declaração parte de um sentimento de orgulho do produtor, porém não pode ser tomada como uma posição consensual dos atores no contexto em que Rio das Ostras vive atualmente. Com os cortes aos royalties de petróleo da Bacia de Campos, localizada em Macaé, a cidade se encontra em um período de recessão econômica, no qual qualquer gasto precisa ser avaliado com cautela pelas autoridades locais. Muitas delas se mostram reticentes à estratégia de se investir só num perfil cultural para a cidade. Na concepção do prefeito da cidade em 2016, Alcebíades Sabino, o festival de jazz não mantém por si uma vida cultural pulsante e econômica na cidade e neste sentido são necessárias outras estratégias para o desenvolvimento da região. De acordo com ele:

Não é uma medida isolada que vai solucionar as dificuldades da cidade. O Festival de Jazz sozinho não dá conta de tudo. A gente aqui em Rio das Ostras já trouxe o Teatro Municipal para dançar em praça pública. A gente já trouxe a Orquestra Sinfônica Brasileira para tocar na praia para gente. [...] A gente fala muito do Festival de Jazz, pois se tornou mais forte até do ponto de vista da economia, mas nós já tivemos na cidade festivais de cinema, de teatro, dança [...]. O verão exerce por si só uma atração muito grande. Por causa das praias as pessoas já vêm tradicionalmente a Rio das Ostras. O problema é a baixa temporada quando se precisa criar eventos para que as pessoas continuem vindo para cá. Por isso a gestão atual decidiu fazer um esforço de trazer mais eventos fora da temporada, para se continuar gerando uma renda ao longo do ano para todos. vivii

Apesar da falta de apoio dos comerciantes locais e pousadeiros, segundo Ennes (Secretária de Desenvolvimento Econômico e Turismo Rio das Ostras em 2016), ainda que com altos e baixos, as diferentes gestões da prefeitura dos últimos anos têm mantido um compromisso de promover a economia local através do turismo (não necessariamente atrelado apenas ao festival de jazz).

Afinal há outros eventos relevantes no nosso calendário. Temos o Festival de Verão que atrai cerca de cinco mil pessoas a seus concertos trazendo cantores populares como Thiaguinho e Ivete Sangalo [...]. O internacionalmente reconhecido Ostracycle, encontro de motoqueiros, já se encontra em sua vigésima primeira edição e atraiu em 2015 quase 10 mil pessoas para a cidade [...]. Isso sem mencionar o Festival de Gastronomia e Frutos de Mar [...]. Portanto, dificilmente podemos criar um branding territorial de Rio das Ostras apenas atrelado ao jazz. Nosso compromisso é com a necessidade de incrementar a economia da cidade ao longo de todo o ano viiiviii

\footnotetext{
vi Entrevista com Stênio Mattos concedida no dia 13 dezembro de 2016.

vii Entrevista com Alcebíades Sabino concedida no dia 17 novembro de 2016. 


\section{Depoimentos dos artistas locais}

Em 2014, o Festival de Jazz \& Blues de Rio das Ostras inovou em sua programação, e essa iniciativa, de certo modo, foi um divisor de águas para os músicos locais. O evento sempre concedeu espaço para músicos novatos na cena musical nacional, representado pelo palco Novos Talentos, usualmente alocado na Concha Acústica, todo sábado e domingo de festival pela manhã. Além disso, como mencionado por Mattos em seus depoimentos, a Orquestra Kuarup de Rio das Ostras tradicionalmente sempre abre as edições do festival. Naquela edição surgiu a iniciativa de organizar um concurso de bandas locais para que a vencedora tocasse no festival. A medida não foi recebida com particular surpresa (afinal esta vinha dentro de um contexto rotineiro para o evento), mas sim causou perplexidade a quantidade de bandas - 55 grupos musicais locais - que se inscreveram para participar do processo de seleção. As autoridades locais e Mattos afirmaram em depoimentos que "não sabiam de onde tinham vindo tantas bandas". Apesar da invisibilidade, o fato é que vem se formando - ainda que de forma incipiente - uma cena musical de jazz local. De acordo com Júnior Muniz, contrabaixista, a cena local teve início de maneira pouco ambiciosa e, depois, foi ganhando vitalidade.

Um músico de Macaé, Gabriel Santiago, propôs a ideia de criarmos um grupo de estudos. Juntos começamos a acompanhar e garimpar o trabalho de alguns artistas da cidade. Passamos a nos reunir algumas horas por semana. E, assim, com o tempo, o nosso grupo foi ganhando corpo [...]. ${ }^{\text {ixix }}$

Outro membro do mencionado grupo de estudos, Eduardo Bruno, saxofonista confirma: "A gente pegava o material de estudo e ia tocar juntos. A gente passou a participar de algumas festas coorporativas, em restaurantes e bares. No Botequim do Adonias, em Macaé, a gente inaugurou esta casa noturna com jazz"x. Ambos os músicos contaram ainda que aprenderam a tocar na Igreja e na Fundação Rio das Ostras de Cultura. É interessante então perceber alguns fatores salientados nos relatos acima. Primeiramente o papel educativo das igrejas e da Fundação de Cultura local formando músicos. Em segundo lugar, a maioria dos músicos entrevistados destaca que ingressou no meio artístico por vontade própria e, inicialmente, sem incentivo ou influência alguma das autoridades locais. Percebe-se então de maneira curiosa que a cidade de Rio das Ostras possivelmente já possuía algum nível de potencial artístico para o desenvolvimento de uma cena musical muito antes desse festival chegar à cidade e/ou de serem implementadas políticas públicas de capacitação da população local.

Outro aspecto que vem à tona nesses depoimentos é o clima de insatisfação e frustração entre os músicos. Se, por um lado, a banda vencedora, chamada Segundo Set, de fato tocou por alguns minutos durante a edição de 2014 (e abriu o palco principal da Costa Azul em 2015), por outro, esses pequenos incentivos não parecem ter composto uma grande mudança para que a cena local de música da cidade se desenvolvesse ao longo dos anos. De acordo com o músico Diego Freitas: "se a gente for hoje depender do jazz, a gente morre de fome [...]". . gravite em torno do jazz, a não ser o festival”. xixi Os músicos contam em depoimentos que a grande maioria os bares e restaurantes locais ainda não aprova inteiramente o repertório de jazz (e blues). Assim, a maior parte das apresentações que os artistas realizam fora do período do festival realizam está associada a um repertório baseado em músicas mais típicas da região litorânea (tais como funk, sertanejo universitário, axé, pop e MPB).

ix Entrevista com Geraldo Muniz Junior concedida no dia 30 julho de 2015.

X Entrevista com Eduardo Bruno concedida no dia 30 julho de 2015.

xi Entrevista com Diego Freitas concedida no dia 30 julho de 2015 
Além da falta de apoio, os músicos lamentam a sazonalidade do festival, a sua realização apenas anual. Neste sentido, Magno Silva, baterista local faz o seguinte comentário: "quando vai se aproximando o festival eu lanço as mãos para o céu e agradeço que está chegando o evento de jazz e que vou ouvir música boa [...] e a galera daqui curte muito tocar e ouvir jazz” xiixiii. E completa: “é uma pena que o evento é realizado só uma vez por ano". xivxiii

\section{Depoimentos dos pousadeiros}

As tensões entre o setor de hotelaria e a prefeitura também estão presentes e vêm se intensificando nos últimos anos por conta da crise econômica e com a redução da margem de lucro das pousadas. Assim, embora a atração de turistas para a cidade seja identificada como uma justificativa forte para o investimento na ocorrência regular do evento na cidade, em geral os pousadeiros se mostram pouco receptivos à ideia de apoiar (como patrocinadores) o evento (cedendo, por exemplo, quartos para convidados e para o staff do festival). De acordo com o proprietário Damião Alves: "Nunca apoiei, pois a cidade não oferece nada ao setor de hotelaria". xvxiv Janaína Gomes, da Pousada do Bosque, tem a mesma opinião e ainda aponta reconhecer como responsabilidade da prefeitura a execução do evento e incentivo ao gênero:

Não temos interesse em investir em eventos deste tipo. Acredito que esses eventos tenham que ser financiados pela prefeitura [...] Sem falar que, com esta crise, ninguém tem moral para pedir ajuda para as pousadas ou para os pequenos comerciantes locais que estão passando por enormes dificuldades [...]. ${ }^{\text {vvixu }}$

Um argumento semelhante foi apresentado por Marília Bussinger:

Os eventos culturais sempre foram da alçada da prefeitura [...]. O comércio local não tem esses recursos para colaborar. É preciso buscar patrocinadores fortes que não existem na cidade. Ninguém nunca me pediu para patrocinar, mas acho que não apoiaria. E nunca vi patrocínio de comerciante pequeno. Para mim sempre tudo esteve relacionado aos royalties do petróleo e agora que acabou a prefeitura tem tido dificuldade em manter o calendário de eventos. ${ }^{\text {xvixui }}$

Nota-se, portanto, uma percepção do empresariado local de que um evento da envergadura do Festival do Jazz \& Blues de Rio das Ostras precisaria ser apoiado pela prefeitura e/ou grandes empresas. Apesar disso, tanto Mattos quanto Sabino afirmaram em depoimentos que seguem tendo a expectativa de que os pousadeiros e comerciantes venham a contribuir de forma mais efetiva com o evento no futuro. Existe, portanto, por parte dos atores locais um consenso em relação a relevância do evento, mas ao mesmo tempo uma discordância sobre quem deve se responsabilizar pela sua viabilização. Além disso, foi possível atestar na pesquisa que a ausência fóruns envolvendo lideranças, autoridades, músicos, comerciantes e pousadeiros locais parece dificultar significativamente o processo de integração do território e as possíveis sinergias que poderiam ser produzidas ali.

\footnotetext{
xiii Entrevista com Magno Silva Souza concedida no dia 30 julho de 2015.

xiv Idem.

xV Entrevista com Damião Alves concedida no dia 15 dezembro de 2016.

xvi Entrevista com Janaína Gomes concedida no dia 23 dezembro 2016. 


\section{Considerações preliminares de um estudo em curso}

Evidentemente, constatam-se algumas contradições presentes na cidade. Por um lado, há uma grande aprovação e alguns resultados significativos - do ponto de vista da melhoria da "qualidade de vida e bemestar"xviixvii da população local - que já foi alcançada através do festival (e com a ajuda dos recursos dos royalties do petróleo designados para a região); e, por outro, até o momento há não só uma incapacidade de absorver a cultura do jazz ao longo do ano (promovendo uma cena local mais consistente de música), mas também grandes dificuldades de se desenvolver uma estratégia clara capaz de incrementar ainda mais o turismo local convertendo a cidade de Rio das Ostras em uma espécie de cidade criativa do estado do Rio de Janeiro. Provavelmente esta dificuldade está associada à falta de uma cultura associativista dos atores do território. Talvez o esforço de criação do Fundo e Conselho Municipal de Cultura seja um passo importante na direção da ampliação do diálogo e na adoção de uma postura mais colaborativa entre os atores. Ambos poderão possibilitar que se alcance novos patamares de desenvolvimento local e que se amplie os processos democráticos (e mais endógenos) na região.

Apesar dos desafios e das contradições assinalados aqui, vale sublinhar que Rio das Ostras possui potencial para se consolidar como uma cidade criativa. Poder-se-ia afirmar que a cidade tem: determinadas instituições de formação artística e culturais atuantes; mão de obra qualificada (inclusive a população local está mobilizada e interessada no desenvolvimento do setor de turismo e entretenimento); e algumas políticas públicas implementadas (com certa continuidade) que vêm possibilitando o crescimento (ainda que lento e gradual) de uma cena cultural local atraente ${ }^{\text {xixxviii }}$. Além disso, esse município já ocupa um lugar no imaginário do estado do Rio (e do país), o que vem garantindo à localidade de Rio das Ostras um fluxo significativo e constante de visitantes e veranistas. Evidentemente esse volume de turistas poderá vir a ser ampliado nos próximos anos, caso não só se superem alguns impasses presentes no território, mas também ocorra um abrandamento da crise econômica em escala nacional.

\section{Referências}

1. Attali J. Ruídos. México: Siglo Veintiuno; 1995.

2. Herschmann M., Fernandes, C.S. Música nas ruas do Rio de Janeiro. São Paulo: Intercom; 2014.

3. Herschmann, M. Apontamentos sobre o crescimento do Carnaval de rua no Rio de Janeiro no início do século 21. Revista Intercom. São Paulo: INTERCOM, v.36, n.2, p. 267-289, jul./dez. 2013.

4. Hall S. Da Diáspora. Belo Horizonte: UFMG; 2003.

5. De Certeau M. A invenção do cotidiano. Petrópolis: Vozes; 1996.

6. Bennett A et al. The Festivalization of Culture. Farham: Ashgate; 2014.

7. Reis A.C. Cidades Criativas. São Paulo: SESI-SP; 2012.

8. Herschmann M, Fernandes C.S. Nova Orleans não é aqui?. Compós [Internet]. 2012 [citado em 10 Maio 2017]; 15(2). Disponível em: http://www.bu.ufsc.br/ccsm/vancouver.html\#pseis

xviii Emprega-se o conceito de 'saúde' de forma ampliada neste artigo' ${ }^{19}$. Em outras palavras, considera-se aqui a ampliação do acesso à vida cultural não só como forma de incremento do bem-estar da população dessa urbe, mas também como importante indicativo dos patamares significativos de desenvolvimento local alcançados pela localidade.

xix Como já sublinhado neste artigo a Universidade Federal Fluminense e a Fundação Rio das Ostras de Cultura (FROC) vêm exercendo um papel importante na formação e capacitação de mão de obra qualificada para a cidade (capaz de atuar no setor de hotelaria, cultural e gastronomia). Sobre a importância dessas instituições Carla Ennes afirma em entrevista concedida a Indira Rodrigues no dia 7 de julho de 2015 em Rio das Ostras: "Já tínhamos uma escola de música na cidade, que funcionava dentro do centro de formação artística, que era ligado à Fundação de Cultura e aí a gente passou a ter também um movimento dos alunos que estavam se formando aqui. Tanto que os músicos que vinham se apresentar já vinham com a disposição de dar um workshop para os interessados na cidade. Depois, com o curso de Produção Cultural da UFF, entendeu-se que esse workshop era não só para a área musical, mas também para os produtores de eventos culturais em geral” (ENNES, Carla. Entrevista concedida a Indira Rodrigues. Rio das Ostras, 7 jul. 2015) 
9. Barbosa L, Zamot F. Políticas públicas para o desenvolvimento do turismo: o caso do município de Rio das Ostras. In: Barbosa L et al., editores. Gestão em turismo e hotelaria. São Paulo: Aleph; 2004.

10. Negus, K. Géneros musicales y la cultura de las multinacionales. Barcelona: Paidós; 2005.

11. Canclini, Néstor G. Conflictos interculturales. Barcelona: Gedisa; 2011.

12. Straw W. Scenes and Sensibilities. COMPÓS [Internet]. 2006 [citado em 10 maio 2017]; (6). Disponível em: http://compos.org.br/seer/index.php/e-compos/article/viewFile/83/83.

13. Yúdice G. A funkificação do Rio. In: Herschmann M. editor. Abalando os anos 90. Rio de Janeiro: Rocco; 1997.

14. Maffesoli M. Sobre o Nomadismo. Rio de Janeiro: Record; 2001.

15. Jenkins H. Fans, bloggers and gamers. Nova York: New York University Press; 2006.

16. Fischer, T. (org.). Gestão do desenvolvimento e poderes locais. Salvador: Ed. Casa da Qualidade; 2002.

17. Buarque S.C. Construindo o desenvolvimento sustentável. Rio de Janeiro: Garamond; 2008.

18. Cocco G, et al. editores Capitalismo Cognitivo. Rio de Janeiro: Ed. DP\&A; 2003.

19. Minayo, MCS, et al. Qualidade de vida e saúde: um debate necessário. Ciência \& Saúde Coletiva. 2000; 5(1): 7-18. 